\title{
Florence Orwat, L'invention de la rêverie. Une conquête pacifique du Grand Siècle
}

\section{Laura Rescia}

\section{Q OpenEdition}

1 Journals

\section{Edizione digitale}

URL: http://journals.openedition.org/studifrancesi/8890

DOI: 10.4000/studifrancesi.8890

ISSN: 2421-5856

\section{Editore}

Rosenberg \& Sellier

\section{Edizione cartacea}

Data di pubblicazione: 1 octobre 2008

Paginazione: 447

ISSN: 0039-2944

\section{Notizia bibliografica digitale}

Laura Rescia, «Florence Orwat, L'invention de la rêverie. Une conquête pacifique du Grand Siècle», Studi Francesi [Online], 155 (LII | II) | 2008, online dal 30 novembre 2015, consultato il 14 janvier 2021. URL: http://journals.openedition.org/studifrancesi/8890 ; DOI: https://doi.org/10.4000/studifrancesi.8890

Questo documento è stato generato automaticamente il 14 janvier 2021.

\section{(c) (i) (9)}

Studi Francesi è distribuita con Licenza Creative Commons Attribuzione - Non commerciale - Non opere derivate 4.0 Internazionale. 


\title{
Florence Orwat, L'invention de la rêverie. Une conquête pacifique du Grand Siècle
}

\author{
Laura Rescia
}

\section{NOTIZIA}

FLORENCE ORWAT, L'invention de la rêverie. Une conquête pacifique du Grand Siècle, Paris, Champion, 2006, pp. 521.

1 Il concetto di rêverie, già oggetto di numerosi studi e ricerche per quanto riguarda il secolo dei Lumi, era stato poco indagato nella letteratura francese secentesca, se non frammentariamente. L'A. ha voluto ricostruire uno sguardo d'insieme sul passaggio della tematica dal mondo antico a quello moderno, attraverso la rilettura di grandi testi del XVII secolo.

2 La prima parte tenta di delineare i limiti concettuali del termine, con l'aiuto di analisi lessicografiche e lessicologiche, sempre ricondotte ai testi dell'epoca prescelta. Il semantismo del verbo rêver e del sostantivo rêverie esprimono, fin dalle prime occorrenze in lingua francese, il rapporto con il vagabondaggio mentale, una sorta di spazio di libertà ai confini della normalità, che può incarnarsi nell'ombra dell'umor nero, ma anche esprimere stati mentali più lievi, ludici e creativi. Se il problema metodologico di fondo, legato all'oscillazione del semantismo terminologico, non sempre viene risolto, si tenta comunque di delineare una successione cronologica che renda evidente l'evoluzione concettuale, attraverso l'individuazione del prevalere di specifiche accezioni del binomio rêver/rêverie: mentre i primi trent'anni del XVII secolo sembrano ancora influenzati dall'accezione medica, che rinvia alle zone oscure della melanconia e del delirio, nel trentennio successivo si individuano le prime emergenze del senso moderno, che connota positivamente il termine, come verrà segnalato nell'opera dei lessicografi della fine del secolo. 
3 Nella seconda parte del suo lavoro, l'a. si concentra sull'analisi della tematica nei diversi generi letterari: se le pagine dedicate al teatro sono piuttosto rapide, la poesia $\mathrm{e}$ il romanzo sono indagati con maggiore attenzione, quest'ultimo essendo individuato come depositario dei prodromi del semantismo moderno e positivo della rêverie. Una dettagliata analisi è riservata a due romanzi maggiori del secolo: in primo luogo l'Astrée, in quanto modello esemplare della dolcezza dell'otium, non priva di ombre e tormenti, e per la ricchezza di variazioni sul tema. Di particolare suggestione sono le pagine dedicate alla retorica del corpo, che apre all'ipotesi di un possibile passaggio alla spettacolarizzazione della gestualità dei personaggi di d'Urfé nelle numerose pièces tratte dal romanzo. Per quanto riguarda Le Page disgracié, viene proposta una lettura del ritmo narrativo che sarebbe informato alla rêverie, e all'ideale della malinconia, letta attraverso i simbolismi e i repertori sintomatici della prevalenza dell'umor nero presenti nella filigrana del romanzo. L'A. esamina poi l'estetica galante e la scrittura femminile delle Précieuses, portate ad esempio dell'affezione del Grand Siècle per la rêverie, concetto che sembra permeare anche la letteratura morale e filosoficoscientifica del secondo Seicento. L'ultimo capitolo sottolinea il ruolo giocato dall'emergenza di spazi privati nella vita sociale della seconda metà del xvII secolo, che consentirebbero la nascita di una nuova concezione dell'intimità e conseguentemente la possibilità di sviluppare lo spazio psichico necessario alla pratica della rêverie, un luogo interiore dove la coscienza può oscillare tra sogno, sonno e realtà.

4 Se non tutti i capitoli appaiono pienamente convincenti, in particolare per l'eterogeneità del campo di analisi, non sempre facilmente riconducibile a conclusioni stringenti, è indubbio il merito dello sforzo di sintesi di un concetto che, per sua stessa natura, si rivela sfuggente e refrattario a definizioni e periodizzazioni. 